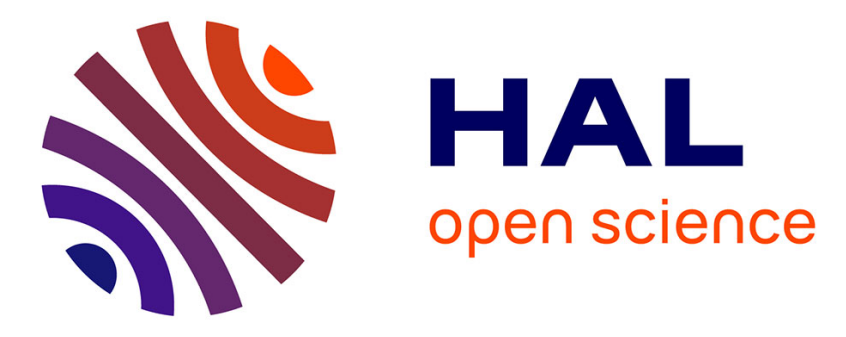

\title{
Transient Cooling of Electronic Components by Flat Heat Pipes
}

\author{
Souad Harmand, Raymond Sonan, Michel Fakès, Hamdy Hassan
}

\section{To cite this version:}

Souad Harmand, Raymond Sonan, Michel Fakès, Hamdy Hassan. Transient Cooling of Electronic Components by Flat Heat Pipes. Applied Thermal Engineering, 2011, 10.1016/j.applthermaleng.2011.02.034 . hal-00743915

\section{HAL Id: hal-00743915 https://hal.science/hal-00743915}

Submitted on 22 Oct 2012

HAL is a multi-disciplinary open access archive for the deposit and dissemination of scientific research documents, whether they are published or not. The documents may come from teaching and research institutions in France or abroad, or from public or private research centers.
L'archive ouverte pluridisciplinaire HAL, est destinée au dépôt et à la diffusion de documents scientifiques de niveau recherche, publiés ou non, émanant des établissements d'enseignement et de recherche français ou étrangers, des laboratoires publics ou privés. 


\section{Accepted Manuscript}

Title: Transient Cooling of Electronic Components by Flat Heat Pipes

Authors: Souad Harmand, Raymond Sonan, Michel Fakès, Hamdy Hassan

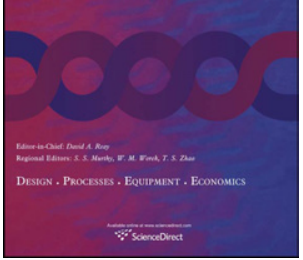

PII:

S1359-4311(11)00115-3

DOI:

10.1016/j.applthermaleng.2011.02.034

Reference: $\quad$ ATE 3445

To appear in: Applied Thermal Engineering

Received Date: 31 August 2010

Revised Date: 26 January 2011

Accepted Date: 20 February 2011

Please cite this article as: S. Harmand, R. Sonan, M. Fakès, H. Hassan. Transient Cooling of Electronic Components by Flat Heat Pipes, Applied Thermal Engineering (2011), doi: 10.1016/ j.applthermaleng.2011.02.034

This is a PDF file of an unedited manuscript that has been accepted for publication. As a service to our customers we are providing this early version of the manuscript. The manuscript will undergo copyediting, typesetting, and review of the resulting proof before it is published in its final form. Please note that during the production process errors may be discovered which could affect the content, and all legal disclaimers that apply to the journal pertain. 


\title{
Transient Cooling of Electronic Components by Flat Heat Pipes
}

\author{
Souad Harmand $^{12 *}$, Raymond Sonan ${ }^{12}$, Michel Fakès ${ }^{3}$, Hamdy Hassan ${ }^{124}$ \\ 1 Université de Lille Nord de France, F-59000 Lille - France \\ 2 UVHC/TEMPO, F-59313 Valenciennes - France \\ 3 Valeo Electrical Systems, 94017 Créteil - France \\ 4 Mechanical Eng. Department, Faculty of Engineering, Assuit University - Egypt \\ * Corresponding author. Tel.: +33 32751 19 74; fax: +33 327511961 \\ E-mail address: souad.harmand@univ-valenciennes.fr (S. Harmand)
}

\begin{abstract}
This paper presents a theoretical investigation of a Flat Heat Pipe (spreader) designed for the cooling of multiple electronic components in transient state. This model is a transient model, coupling 3D thermal model with a 2D hydrodynamic one through the mass flux of evaporation-condensation, which occurs in a mass conservation equation. The model makes it possible to obtain the FHP wall transient temperatures, the transient pressures, velocities and temperatures in both liquid and vapor phases. A comparison of the behaviour of the FHP and an equivalent solid plate submitted to a transient thermal cycle shows that the FHP enhanced the electronic components cooling for the long thermal cycle duration when the solid plate is more efficient for the very short transient thermal cycles. The FHP provides also a very low thermal resistance which helps to minimise the temperature gradient and then the hot spots and overheating.
\end{abstract}

Keywords: Heat pipe, spreader, condensation, evaporation, transient cooling, electronics components

\section{Nomenclature}

$C_{E}$ Ergun coefficient

$\varepsilon \quad$ porosity of the wick

$C_{p} \quad$ specific heat capacity

$J . \mathrm{kg}^{-1} . K^{-1} \quad \lambda \quad$ thermal conductivity $W \cdot K^{-1} \cdot m^{-1}$

$H$ height, thickness m

$\mu \quad$ dynamic viscosity Pa.s 


\begin{tabular}{|c|c|c|c|c|c|}
\hline$H$ & heat transfer coefficient & $W \cdot K^{-1} \cdot m^{-2}$ & & kinematic viscosity & $m \cdot s^{-2}$ \\
\hline$h_{f g}$ & latent heat of vaporisation & $J . k g^{-1}$ & $\rho$ & density & kg. $\mathrm{m}^{-3}$ \\
\hline$K$ & permeability & $m^{2}$ & $\varphi$ & heat flux density & $W . m^{-2}$ \\
\hline$L$ & length & $m$ & & & \\
\hline$\dot{m}$ & mass flow rate & $k g . s^{-1}$ & \multicolumn{2}{|c|}{ Subscripts } & \\
\hline$p$ & pressure & $\mathrm{Pa}$ & $a$ & ambiant, adiabatic & \\
\hline$r$ & pore radius & $m$ & $c$ & condenser & \\
\hline$T$ & temperature & $K$ & $e$ & evaporator & \\
\hline$t$ & time & $s$ & eff & effective & \\
\hline$u, v$ & velocity & $m \cdot s^{-1}$ & $e q$ & equivalent & \\
\hline$V$ & volume & $m^{3}$ & $l$ & liquid & \\
\hline$\vec{V}$ & velocity vector & $m \cdot s^{-1}$ & $\mathrm{M}$ & matrix & \\
\hline \multicolumn{2}{|c|}{$x, y, z$ coordinates } & $m$ & $\begin{array}{l}\text { sat } \\
v\end{array}$ & $\begin{array}{l}\text { saturation } \\
\text { vapor }\end{array}$ & \\
\hline \multicolumn{3}{|c|}{ Greek symbols } & $w$ & heat pipe wall & \\
\hline & mass flow rate & $k g \cdot s^{-1} \cdot m^{-3}$ & wi & wick & \\
\hline
\end{tabular}

\section{Introduction}

The thermal management of electronic components operating with fast transients is presently a crucial problem arising in many application fields. The automobile industry is a strong example focusing its efforts on developing new Powertrain Efficiency innovations in order to create vehicles that are more fuel efficient and thus less polluting. This in order to reconcile cars and society with the objective of zero pollution and to respect the new European emissions regulations. One of these innovations, the hybrid starter-alternator [1] technology, provides an interesting solution that meets society's need for cars with lower fuel consumption and lower pollution emissions. The Stop \& Start function of the starter-alternator turns the engine off automatically when the vehicle comes to a standstill (red lights, temporary halts, traffic jams, etc.) and restarts the engine instantly and silently as soon as the driver releases the brake pedal or accelerates. Depending on the vehicle and the engine, the Stop \& Start system provides fuel savings of around $10 \%$ for city driving and $6 \%$ in standard combined cycles. The hybrid starter- 
alternator is subject to high current cycles, which causes increased heat flux generated $\left(60\right.$ to $400 \mathrm{~W} / \mathrm{cm}^{2}$ ) by the electronic components in the device. Dissipating these fluxes inside the components can cause such thermal problems as overheating $\left(175^{\circ} \mathrm{C}\right)$, which can reduce the components performance levels as well as their lifespan. For this reason, managing the thermal dissipation in electronic components, while maintaining their temperatures within the specified temperature range, has become a crucial factor for safety and reliability in numerous engineering domains.

As an answer to this problem, flat heat pipes (also called two-phase heat spreaders) of various types have been investigated by the researcher community. Heat pipes have inherent advantages and much potential for managing heat in electronic equipments due to their effective performance and their ability to provide effective heat transfer with minimal losses [2]. Over the last few years, the use of heat pipes for thermal management has been increasingly investigated [3]. According to Garimella and Sobhan [4], heat pipe operation and performance have been widely analyzed. Flat heat pipes (FHP) are an efficient technology for cooling electronic components due to their high thermal conductivity, reliability and flexible configurations. An FHP is a sealed chamber whose inner surface is lined with a capillary wick material [5]. It is partially filled with working fluid, which is vaporized by an external heat source (e.g., an electronic component) at the evaporator. The pressure difference thus generated drives vapor to the condenser, where it condenses. The capillary pressure in the wick pumps the condensed liquid back to the evaporator. As long as sufficient capillary pressure is maintained, this internal phase-change circulation will continue.

However, the coupled thermal and hydraulic problems in such heat pipes operating at transient state is a complex study, witch was not much treated until now. In this article, we present a model for analyzing the performance of a FHP subjected to heat from multiple electronic components during a short transient period (figure1). This model is based on a transient 3D thermal model coupled to a transient 2D hydrodynamic model that computes the flow in the wick and the vapour core. This model allows the transient heat diffusion in the FHP to be taken into account. The mass and heat transfers related to the liquid-vapor phase change are computed with an energy balance equation. The hydrodynamic model is coupled to the thermal model through the mass evaporation- 
condensation flux, which occurs in the mass conservation equation of the Transient 2D Hydrodynamic model.

In this work, we present a simplified but robust model able to capture the thermal behaviour of the flat heat pipe operating in the transient state. This model is well appropriate for use in the Flat Heat Pipe design process for the thermal management of electronic components.

\section{Mathematical model}

The 3D Transient Thermal and Hydrodynamic model is composed of a 3D transient thermal model coupled with a 2D transient hydrodynamic model. The model has two stages. First, the transient thermal conduction throughout the FHP wall is determined using the $3 \mathrm{D}$ thermal model, which is able to precisely evaluate the local heat exchanges within the heat pipe. These exchanges cause the phase change and initiate the fluid transport $[6,7,8,9]$. The fluid flow, both vapor and liquid, is then determined using the $2 \mathrm{D}$ hydrodynamic model. The fluid velocity distribution is used to systematically calculate the rate of evaporation-condensation.

The FHP geometry studied is shown in Figure 1. The electronic components represent the heat sources (evaporators), which are posed on the upper surface of the FHP and the fins represent the cold sources (condensers), which are posed on the lower surface. The capillary structure (i.e., the porous wick) is enclosed in the internal FHP wall. In this study, it is assumed that the fluid flow is $2 \mathrm{D}$ ( $x \& y$ planes) and laminar. We use the $2 \mathrm{D}$ transient model to determine the fluid transport through the wick and the vapor core, adapting the hydrodynamic approach suggested by Lefèvre and Lallemand[10] and Huang et al.[11]. Unlike these authors, we do not adopt the simplified Darcy assumption for the liquid flow through the porous wick. We take the general pressure into account as transient phenomena.

The 2D transient model is coupled with a 3D transient thermal model of the FHP wall, which makes it possible to characterize the transitory heat diffusion in the FHP wall. The mass transfers associated with the liquid-vapor phase change are used to define the boundary conditions of the thermal problem. The pressure and velocity distribu- 
tions are calculated by taking to account the movement of the liquid in the porous media. All the free wall surfaces are assumed to be adiabatic. The capillary structure in which the liquid circulates is equivalent to a porous medium characterized by its permeability $K$, porosity $\varepsilon$ and the equivalent pore radius $r_{e q}$. The fluid flows are assumed to be laminar and incompressible.

The heat transfers in the FHP wall can be expressed with the following equation:

$$
\left(\rho \mathrm{C}_{\mathrm{p}}\right)_{\mathrm{w}} \frac{\partial \mathrm{T}}{\partial \mathrm{t}}-\lambda_{\mathrm{wa}}\left[\frac{\partial^{2} \mathrm{~T}}{\partial \mathrm{x}^{2}}+\frac{\partial^{2} \mathrm{~T}}{\partial \mathrm{y}^{2}}+\frac{\partial^{2} \mathrm{~T}}{\partial \mathrm{z}^{2}}\right]=0
$$

The boundary conditions associated to the thermal problem are described as:

at evaporator:

$$
\begin{aligned}
& -\lambda_{\mathrm{w}}\left(\frac{\partial \mathrm{T}}{\partial \mathrm{z}}\right)_{\mathrm{z}=\mathrm{Lz}} \mathrm{dxdy}=\varphi_{\text {in }} \mathrm{dxdy} \\
& -\lambda_{\mathrm{w}}\left(\frac{\partial \mathrm{T}}{\partial \mathrm{z}}\right)_{\text {upper wall }} \mathrm{dxdy}=\mathrm{h}_{\mathrm{eq}, \mathrm{w}} \mathrm{dxdy}\left(\mathrm{T}-\mathrm{T}_{\text {sat }}\right)+\delta^{2} \dot{\mathrm{m}}_{\mathrm{e}} \mathrm{C}_{\mathrm{pl}} \mathrm{T}_{\text {sat }}=\varphi_{\text {upper wall }} \mathrm{dxdy} \\
& -\lambda_{\mathrm{w}}\left(\frac{\partial \mathrm{T}}{\partial \mathrm{z}}\right)_{\text {lower wall }} \mathrm{dxdy}=\mathrm{h}_{\mathrm{eq}, \mathrm{w}} \mathrm{dxdy}\left(\mathrm{T}_{\text {sat }}-\mathrm{T}\right)+\delta^{2} \mathrm{~m}_{\mathrm{c}} \mathrm{C}_{\mathrm{pl}} \mathrm{T}_{\text {sat }}=\varphi_{\text {lower wall }} \mathrm{dxdy}
\end{aligned}
$$

at the finned wall: $-\lambda_{\mathrm{w}}\left(\frac{\partial \mathrm{T}}{\partial \mathrm{z}}\right)_{\mathrm{z}=0} \mathrm{dxdy}=\mathrm{h}_{\mathrm{c}}\left(\mathrm{T}-\mathrm{T}_{\mathrm{a}}\right) \mathrm{dxdy}$

where $h_{e q, w}=\frac{\lambda_{e f f}}{H_{l}}$ characterizes the wick's thermal conductance.

It is generally accepted in the literature that the temperature $T_{\text {sat }}$ is constant [6], we do not make this assumption in this model. Instead, we take into account the dependence of $T_{\text {sat }}$ on time and space (i.e, $T_{s a t}=T_{s a t}(\mathrm{x}, \mathrm{y}, \mathrm{t})$ ). Indeed, the $T_{s a t}$ distribution depends on the distribution of the evaporators and condensers over the FHP wall.

We assume that the FHP wick is always filled with liquid. The 3DTH model integrates the mass conservation equation into the momentum equation to obtain a secondorder differential equation that uncouples pressure and velocity. By considering an ele- 
mentary volume $\mathrm{dV}_{1}=\mathrm{dx} \times \mathrm{dy} \times \mathrm{H}_{1}$ of liquid, the energy assessment in a quasi-static approximation can be written as: $\varphi_{0} d x d y=\delta^{2} \dot{m} h_{f g}$

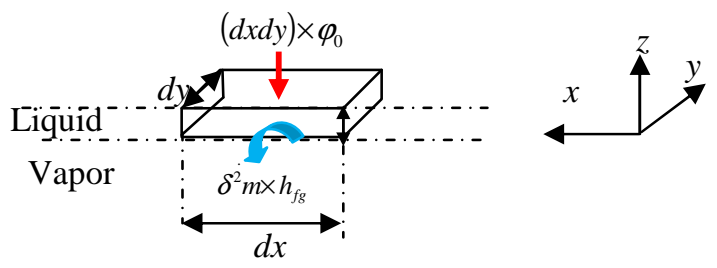

where $\varphi_{0}$ denoted the wall heat flux, expressed in the thermal model as:

$\varphi_{0}=\left\{\begin{array}{l}\varphi_{\text {upper wall }}: \text { at the upper int erface liquid/vapour } \\ \varphi_{\text {lower wal }}: \text { at the lower int erface liquid/vapour }\end{array}\right.$

$\delta^{2} m$ is the elementary mass flow corresponding to the liquid mass injection or rejection within an elementary control volume. The mass flow $\delta^{2} \dot{m}$ depends on the liquid velocity expressed with the mass conservation equation as:

$\delta^{2} \dot{m}=\delta^{2} \dot{m}_{x}+\delta^{2} \dot{m}_{y}=\rho_{l} d y H_{l} d u_{l}+\rho_{l} d x H_{l} d v_{l}$

Combining the above equations, the differential mass equation describes the relationship between the fluid velocity and the thermal model:

$$
\frac{\partial \mathrm{u}_{1}}{\partial \mathrm{x}}+\frac{\partial \mathrm{v}_{1}}{\partial \mathrm{y}}=\frac{\alpha_{1}}{\rho_{1}}, \quad \alpha_{1}=\frac{\varphi_{0}}{\mathrm{~h}_{\mathrm{fg}} \mathrm{H}_{1}}
$$

The liquid flow through the wick is governed by the momentum equation:

$$
\frac{\mathrm{D}}{\mathrm{Dt}}\left(\frac{\rho}{\varepsilon} \overrightarrow{\mathrm{V}}\right)=-\overrightarrow{\operatorname{grad}}(\mathrm{p})+\frac{\mu}{\varepsilon} \nabla \cdot(\nabla \cdot \overrightarrow{\mathrm{V}})-\frac{\mu}{\mathrm{K}} \overrightarrow{\mathrm{V}}-\frac{\mathrm{C}_{\mathrm{E}}}{\mathrm{K}^{1 / 2}} \rho|\overrightarrow{\mathrm{V}}| \overrightarrow{\mathrm{V}}
$$

Where $C_{E}$ is the Ergun coefficient, whose typical value is 0.55 .

As indicated, the objective of the work is to develop a simplified but robust model able to capture the thermal behaviour of flat heat pipe operating in transient state, considering the approximation, $\frac{\mu}{\varepsilon} \nabla \cdot(\nabla \cdot \vec{V}) \approx \frac{C_{E}}{K^{1 / 2}} \rho|\vec{V}| \vec{V}$, and projecting the momentum equation over the (x, y) plane yields: 


$$
\begin{aligned}
& \frac{\rho}{\varepsilon}\left(\frac{\partial u_{l}}{\partial t}+u_{l} \frac{\partial u_{l}}{\partial x}+v_{l} \frac{\partial u_{l}}{\partial y}\right)=-\frac{\partial p_{l}}{\partial x}-\frac{\mu_{l}}{K} u_{l} \\
& \frac{\rho}{\varepsilon}\left(\frac{\partial v_{l}}{\partial t}+u_{l} \frac{\partial v_{l}}{\partial x}+v_{l} \frac{\partial v_{l}}{\partial y}\right)=-\frac{\partial p_{l}}{\partial y}-\frac{\mu_{l}}{K} v_{l}
\end{aligned}
$$

To made the simplification of the momentum equation: $\frac{\mu}{\varepsilon} \nabla(\nabla \vec{V}) \approx-\frac{C_{E}}{K^{1 / 2}} \rho|\vec{V}| \vec{V}$ we have used the justification given in reference [6] and [15]. The more important terms in the second member of equation (5) are mainly the Darcy terms: $-\overrightarrow{\operatorname{grad}}(p)$ and $-\frac{\mu}{K} \vec{V}$

This approximation consist on neglecting the Forchheimer term $-\frac{C_{E}}{K^{1 / 2}} \rho|\vec{V}| \vec{V}$ and Brinkman term $\frac{\mu}{\varepsilon} \nabla(\nabla \vec{V})$ [6], [15], due to the low porosity of the wick and also to the low liquid flow velocities and Reynolds numbers.

When differentiating and arranging these equations according to $x$ and $y$ and considering the equality between $\frac{\partial}{\partial t}\left(\frac{\partial}{\partial x}\right)=\frac{\partial}{\partial x}\left(\frac{\partial}{\partial t}\right)$, the pressure equation can be expressed as:

$$
\frac{\partial^{2} p_{l}}{\partial x^{2}}+\frac{\partial^{2} p_{l}}{\partial x^{2}}=-\frac{\mu_{l}}{K}\left(\frac{\partial u_{l}}{\partial x}+\frac{\partial v_{l}}{\partial y}\right) \frac{\rho_{l}}{\varepsilon}\left[\begin{array}{l}
\frac{\partial}{\partial t}\left(\frac{\partial u_{l}}{\partial x}+\frac{\partial v_{l}}{\partial y}\right)+\left(\frac{\partial u_{l}}{\partial x}+\frac{\partial v_{l}}{\partial y}\right)^{2} \\
+u_{l} \frac{\partial}{\partial x}\left(\frac{\partial u_{l}}{\partial x}+\frac{\partial v_{l}}{\partial y}\right)+v_{l} \frac{\partial}{\partial y}\left(\frac{\partial u_{l}}{\partial x}+\frac{\partial v_{l}}{\partial y}\right)
\end{array}\right]
$$

By using the conservation equation (4), the previous equation becomes:

$$
\begin{aligned}
& \frac{\partial^{2} p_{l}}{\partial x^{2}}+\frac{\partial^{2} p_{l}}{\partial x^{2}}=-\frac{\mu_{l}}{\rho_{l} K} \alpha_{l}-\frac{1}{\varepsilon}\left[\frac{\partial \alpha_{l}}{\partial t}+\frac{\alpha_{l}^{2}}{\rho_{l}}+u_{l} \frac{\partial \alpha_{l}}{\partial x}+v_{l} \frac{\partial \alpha_{l}}{\partial y}\right] \\
& \text { where } \quad \alpha_{l}=\rho_{l}\left(\frac{\partial u_{l}}{\partial x}+\frac{\partial v_{l}}{\partial y}\right)
\end{aligned}
$$

In the following paragraphs, it is assumed that the complete derivative of the mass flow rate $\alpha_{l}$ is equal to its partial derivative according to time: 


$$
\frac{D \alpha_{l}}{D t} \approx \frac{\partial \alpha_{l}}{\partial t} \text { if } \frac{\partial \alpha_{l}}{\partial t}>>u_{l} \frac{\partial \alpha_{l}}{\partial x}+v_{l} \frac{\partial \alpha_{l}}{\partial y}
$$

This assumption can be justified by the fact that the term $u_{l} \frac{\partial \alpha_{l}}{\partial x}+v_{l} \frac{\partial \alpha_{l}}{\partial y}$ is always negligible compared to $\frac{\partial \alpha_{l}}{\partial t}$. Based on this assumption witch is justified in [8] and [14], equation (8) is simplified to give the differential pressure equation according to the flow rate $\alpha_{l}$ :

$$
\frac{\partial^{2} p_{l}}{\partial x^{2}}+\frac{\partial^{2} p_{l}}{\partial y^{2}}=-\frac{\mu_{l}}{K \rho_{l}} \alpha_{l}-\frac{1}{\varepsilon}\left(\frac{\partial \alpha_{l}}{\partial t}+\frac{\alpha_{l}^{2}}{\rho_{l}}\right)
$$

In a steady state, the pressure equation generally used in the literature, where the term $\frac{1}{\varepsilon} \frac{\alpha_{l}^{2}}{\rho_{l}}$ is assumed to be negligible, is recognized to be:

$$
\frac{\partial^{2} p_{l}}{\partial x^{2}}+\frac{\partial^{2} p_{l}}{\partial y^{2}}=-\frac{\mu_{l}}{K \rho_{l}} \alpha_{l}
$$

The previous equation gives the pressure distribution ; knowing this distribution, it's easy to determine the liquid velocity distribution and thus evaluate the flow rate of liquid evaporation, given by:

$$
\dot{m}_{e}=\int \delta^{2} \dot{m}_{e}=\rho_{l} H_{l} \int\left(u_{l} d y+v_{l} d x\right)
$$

For the vapor core, we adopted a similar approach to the one used for the wick to calculate the pressure and velocity fields. We assumed that the vapor velocity $w$ according to transverse axis $z$ is negligible compared to $u$ and $v$. The mass conservation equation is established by analogy with the liquid flow:

$$
\frac{\partial u_{v}}{\partial x}+\frac{\partial v_{v}}{\partial y}=-\frac{\alpha_{v}}{\rho_{v}}, \alpha_{v}=\frac{\varphi_{\text {upper wall }}}{h_{f g} H_{v}}
$$


If the vapor flow is considered like the fluid flow between two flat plates, using the approximation $\mu_{v} \nabla^{2}\left(\overrightarrow{V_{v}}\right) \approx \frac{12 \mu_{v}}{H_{v}^{2}} \overrightarrow{V_{v}}$, justified in [12] and [8], the vapor flow momentum equation can be written:

$\rho_{v}\left(\frac{\partial u_{v}}{\partial t}+u_{v} \frac{\partial u_{v}}{\partial x}+v_{v} \frac{\partial u_{v}}{\partial y}\right)=-\frac{\partial p_{v}}{\partial x}-\frac{12 \mu_{v}}{H_{v}^{2}} u_{v}$
$\rho_{v}\left(\frac{\partial v_{v}}{\partial t}+u_{v} \frac{\partial v_{v}}{\partial x}+v_{v} \frac{\partial v_{v}}{\partial y}\right)=-\frac{\partial p_{v}}{\partial y}-\frac{12 \mu_{v}}{H_{v}^{2}} v_{v}$

By applying the above method to the liquid case, the pressure equation for the vapor flow is expressed as:

$\frac{\partial^{2} p_{v}}{\partial^{2} x}+\frac{\partial^{2} p_{v}}{\partial^{2} y}=\frac{12 \mu_{v}}{H_{v}^{2}} \alpha_{v}+\left(\frac{\partial \alpha_{v}}{\partial t}-\frac{\alpha_{v}^{2}}{\rho_{v}}\right)$

The second term of the right-hand member of this equation is neglected, according to [10], thus the pressure equation is expressed by:

$\frac{\partial^{2} p_{v}}{\partial^{2} x}+\frac{\partial^{2} p_{v}}{\partial^{2} y}=\frac{12 \mu_{v}}{H_{v}^{2}} \alpha_{v}$

By substituting this pressure value in the momentum equation, the vapor velocity is fixed and thus the vapor mass flow rate, $\dot{m}_{c}$ of condensation is calculated with the following integration:

$$
\dot{m}_{c}=\int \delta^{2} m_{c}=\rho_{v} H_{v} \int\left(u_{v} d y+v_{v} d x\right)
$$

The numerical results based on this FHP model are presented in the following section.

\section{Results and discussion}

In order to capture the transient variations with minimal round-off errors, and to simplify the computational scheme, an implicit Euler computational procedure was employed for time differencing. The governing equations were discretized using the finite difference method, and the nonlinear terms in the momentum equations were discretized according to the linearization method suggested by Fletcher [13]. The computational code was written with Matlab ${ }^{\circledR}$. The time step and spatial grid size required for fast 
convergence was determined through trial and error. Temperature, pressure and velocity distributions were calculated successively. The following section compares the results of our model with the results available in the literature.

\subsection{Model validation through comparison with the literature and experimental}

The results of our model are compared below to the analytical results published by Lefèvre and Lallemand [10] for a steady-state operation. Also our numerical model results are validated with the transient experimental and numerical results published by Chen et al. [16]. The aim here is to use the model of Lefèvre and Lallemand [10] and Chen et al. [16] as test-cases in order to validate our numerical model.

The heat pipe considered was a flat copper heat pipe filled with water, measuring $40 \times 40 \times 0.9 \mathrm{~mm}^{3}$. The wall, wick and vapor thicknesses were, respectively, $265 \mu \mathrm{m}, 140$ $\mu \mathrm{m}$ and $230 \mu \mathrm{m}$. The heat sources (three electronics components) all generated the same heat flux: $35 \mathrm{~W} / \mathrm{cm}^{2}$. In their work, Lefevère et al. used Neumann boundary conditions at the condensers area and the saturation temperature, $T_{\text {sat }}$, is fixed equal to $50^{\circ} \mathrm{C}$. The mean difference with our model is that our formulation allows the calculation of the temperature $T_{\text {sat }}$ instead of imposed it as these authors done. In order to simulate the same heat pipe operation, the value of the heat exchange coefficient at condensers, $h_{c d}$, is determined by such that $T_{\text {sat }}$ tends, in average point of view, to equalize the value of $50^{\circ} \mathrm{C}$. Therefore, the equivalent exchange coefficient was about $h_{c d}=4500 \mathrm{~W} / \mathrm{K} \mathrm{m}^{2}$.

The details of the comparison of the results obtained by our model at steady state and those published by Lefèvre and Lallemand [10] are given in [14] and shows that the results of our model correspond well to those of these authors. Indeed, the vapor pressure distribution of our model is similar to the one reported by Lefèvre et al. [10]. They obtained a drop in vapor pressure of about $\Delta P_{v}=1500 \mathrm{~Pa}$, while our model predicts slightly lower, $\Delta P_{v}=1377 \mathrm{~Pa}$. In the liquid flow, the model predicts $\Delta P_{l}=2624 \mathrm{~Pa}$, when the authors obtained $\Delta P_{l}=2600 \mathrm{~Pa}$. Thus the maximum capillary pressure is about $\Delta P_{c}=4001 \mathrm{~Pa}$ with our formulation and about $\Delta P_{c, \max }=4100 \mathrm{~Pa}$ with the model of these authors. That represents a slight difference of $2.4 \%$.

The velocity fields obtained with our model also correspond well to those of Lefèvre [10] with a relative difference of about $4.4 \%$. 
At steady state, the wall temperature determined by our thermal model is close to those of Lefèvre and Lallemand [10] with an absolute deviation of $1 \mathrm{~K}$ as explain in [14].

The heat pipe considered for the comparison of our numerical model results with the experimental and numerical work of Chen et al. [16] has the size of $85 \mathrm{~mm}$ length, $70 \mathrm{~mm}$ width and $5 \mathrm{~mm}$ total thickness with the same construction shown in figure1. The wall thickness is $1 \mathrm{~mm}\left(\mathrm{H}_{\mathrm{w}}\right)$, the vapour thickness is $2 \mathrm{~mm}\left(\mathrm{H}_{\mathrm{v}}\right)$, the wick made of sintered copper powder has a thickness of $0.5 \mathrm{~mm}\left(\mathrm{H}_{1}\right)$, a porosity of 0.36 and an effective thermal conductivity of $10.23 \mathrm{~W} / \mathrm{m} . \mathrm{K}$. The heat pipe is heated by using a copper block heat source with a power input of $50 \mathrm{~W}$ locates at the centre of the heat pipe surface which has the surface area of $20 \times 20 \mathrm{~mm}^{2}$. This heat pipe is insulated by using an insulation of Bakelite. The cooling is carried out by using an aluminium heat sink as shown in figure 1 . The air velocity entering the heat sink is $3 \mathrm{~m} / \mathrm{s}$ and has an ambient temperature of $300 \mathrm{~K}$ [16]. Figure 2a shows the comparison between our numerical results and the experimental and numerical results published by Chen et al. [16] for the evolution of the maximum heat pipe temperature rise versus time. The results are presented in case of considering the effect of heater and insulation materials thickness and in case of neglecting their effect. The results show a good agreement between the numerical results and the experimental and the numerical results of Chen et al. [16]. They also shows that in the case of including heater and insulation material thermal behaviour in the model, the transient temperature rise takes more time to reach a steady state due to the heat absorbed by the heater and insulation material. The evolution of the total mass evaporated and condensed versus time in case of neglecting heater and insulation thickness effect is shown in figure $2 b$. These results are obtained thanks to our numerical model. The figure shows that the total mass evaporated is greater than the total mass condensed until reaching the steady state. We fined that the total mass evaporated equals to the total mass condensed which accords with the physical of the transient process. It also shows that at approaching to steady state, the total mass is about $2 \times 10^{-5}$ $\mathrm{kg} / \mathrm{s}$ which approximately equals to (power input $/$ latent heat $=50 / 2400 \times 10^{3}=2.08 \times 10^{-}$ ${ }^{5}$ ), which validates our numerical results. The comparison of the numerical results for the hotspot of the evaporator surface temperature and condenser surface temperature are shown in figure 3. Figure 3 a shows the results in case of power input $50 \mathrm{~W}$ and heater surface area $20 \times 20 \mathrm{~mm}^{2}$ and figure $3 \mathrm{~b}$ shows the results for power input $40 \mathrm{~W}$, and 
heater surface area of $10 \times 10 \mathrm{~mm}^{2}$. As expected, the spreading resistance increases with smaller heat sources surface area, leading to a larger temperature difference across the vapor chamber as shown in figure $3 \mathrm{~b}$. It can be seen form figure 3 that, the simulated transient responses are in good agreement with the experiments especially when the system approaches to steady state. The maximum difference between the simulations and measurements of the temperature rises is $10 \%$. From the results shown earlier, we find that, the results from our numerical model correspond well to those published in the literature. We present in the next two sub-sections the FHP performances predicted by the 3D Transient Thermal and Hydrodynamic (3DTH) model. The grid mesh used for the calculations is adaptable along the $x$ and $y$ axes. The mesh sizes of the FHP were found to guarantee the good convergence and the precision of the calculations. The model was used to predict some typical electronic component cooling applications using a FHP in both a periodic thermal cycle and in a typical vehicle start-up regime.

\subsection{Application of the 3DTH model to a periodic thermal cycle}

In this section, we describe the results of simulations, run with the FHP shown in figures 1. The FHP was used to cool three electronic components. Each component was assumed to generate a periodic heat flux as shown in figure 4 . The condenser is equipped with a fins and we assumed that the equivalent heat transfer coefficient $h_{c d}=$ $1000 \mathrm{~W} / \mathrm{m}^{2} \mathrm{~K}$ at a reference temperature $T_{a}=25^{\circ} \mathrm{C}$. The initial temperature was about $25^{\circ} \mathrm{C}$, corresponding to a saturation pressure of $3182 \mathrm{~Pa}$.

The following data provide the details about the FHP size and its thermo-physical properties.

$\Rightarrow$ FHP dimensions: $\mathrm{L}_{\mathrm{x}} / \mathrm{L}_{\mathrm{y}}=30 / 30 \mathrm{~cm}, \mathrm{~L}_{\mathrm{z}} / \mathrm{H}_{\mathrm{l}} / \mathrm{H}_{\mathrm{v}}=6.4 / 4.4 / 4 \mathrm{~mm}$,

$\Rightarrow$ wall material/fluid: Copper/Water

$\Rightarrow$ Copper screen powder wick: $\varepsilon=0.9, \mathrm{~K}=1.43 \times 10^{-11} \mathrm{~m}^{2}, \mathrm{r}=1.0192 \times 10^{-6} \mu \mathrm{m}$,

A variety of tests were performed to establish time-step and mesh independence. As the result of the grid independence study, the $300 \times 300 \times 20(x \times y \times z)$ mesh was used for the thermal model. The wick and vapor regions include the same grid point $300 \times 300 \times 1(x \times y \times z)$. The time step of $10^{-3} \mathrm{~s}$ was adequate to ensure convergence and stability of the calculations and to make it possible to capture the problem physics. 
Figures 5 and 6 present the mean temperature response of the FHP subjected to the thermal power released by the electronic component. The FHP performances are compared to those of the solid and the hollow copper plate. The hollow plate behaves similarly to a faulty FHP, or in other words, similar to a heat pipe reaching its operational limits. Thus, the electronic component cooling using the heat pipe is better than the cooling using a hollow plate. However, the difference compared to the solid copper plate is relatively weak. The heat pipe effect (i.e., the heat and mass transfers controlled by evaporation-condensation mechanism) results in a homogeneous heat pipe operation, meaning a closed temperature value at the evaporator and the condenser. Comparing to the solid plate, the main advantage of FHP operation is that it provides a very low thermal resistance, which helps to maintain the same temperature at the two ends of the FHP as shown in figure 7.

\subsection{Application of the 3DTH model to a variable thermal cycle}

Figure 8 shows the plots for the simulations of a typical vehicle start-up regime during which three starter-alternator electronic components sizing $5 \times 7 \mathrm{~mm}^{2}$, dissipate the thermal heat power. The FHP is Copper-Water and measures $35 \times 23 \times 2.8 \mathrm{~mm}^{3}$. The FHP wall, wick and vapor core thicknesses are $1,0.2$ and $0.4 \mathrm{~mm}$, respectively. The same (see sub-section 3.2.) porous structure (i.e., wick) covers the inside of two wall surfaces. The three components simulated the evaporators and were placed on the upper surface of the heat pipe wall. The condenser (cold source) was positioned on the bottom wall surface. The equivalent heat coefficient through the condenser was set to $h_{c d}=40$ $\mathrm{W} \cdot \mathrm{K}^{-1} \cdot \mathrm{m}^{-2}$ at an ambient temperature $T_{a}=20^{\circ} \mathrm{C}$. The wick characteristics were $\varepsilon=$ $0.733, K=0.42 .10^{-10} \mathrm{~m}^{2}$ and $\lambda_{e q}=0.602 \mathrm{~W} \cdot \mathrm{K}^{-1} \cdot \mathrm{m}^{-1}$. We performed a sensitivity study that allowed us to set a suitable time step (about $0.05 \mathrm{~s}$ ) and a grid size of $d x \times d y \times d z=$ $1 \times 1 \times 0.1 \mathrm{~mm}^{3}$.

As shown in figure 9, the maximum temperature value (over the first electronic component) at each time is plotted and compared to that of an equivalent solid copper plate. The copper plate measured $35 \times 23 \times 2.8 \mathrm{~mm}^{3}$ and was subjected to the same heat conditions as the FHP (figure 8). The FHP temperature variation was very sensitive to the imposed heat fluctuation, with the fastest response time. The response time of the solid copper plate was longer because of its greater thermal inertia. Although the tem- 
perature value of the heat pipe in rising phase is greater than the plate's value (deviation about $13^{\circ} \mathrm{C}$ ), the heat pipe did not insures better cooling. Even if the FHP is less efficient in the rising phase, figure 9 show that the FHP cooling is more efficient during the descending phase with a temperature drop of $19^{\circ} \mathrm{C}$ (at $t=10 \mathrm{~s}$ ) in comparison with the solid flat plate. Figure 10 illustrates the temperature distribution over the FHP wall at the end of the rise phase $(t=3 \mathrm{~s})$ where the electronics components were situated. For this kind of thermal cycle, the FHP is more efficient and less heavy than the solid plate. This can constitute an interesting challenge if the mass reduction and the temperature homogenisation is a strong element in the system optimal design as in the land and aeronautic transport systems.

The liquid flows out from the free zones (adiabatic zones) towards the electronics components (Figure 11), where it evaporates (liquid mass absorption) and vapor generation occurs. The liquid at the middle of the wick region is pumped towards the ends ( $x=0$ and $x=35 \mathrm{~mm}$ ), thus feeding the upper wick and the lower wick (figure 12).

The vapor (figure 13) flows in the opposite direction of the liquid (adjunction of vapor mass generation under the component positions). The maximum vapor velocity is about $61 \mathrm{~m} / \mathrm{s}$, corresponding to a Reynolds number of 96 (i.e., laminar flow regime) and a Mach number of 0.05. The Mach number is lower than the unit, thus the FHP sonic limit is not reached. The pressure distribution in the liquid (figures 11 and 12) conforms to the velocity distribution. Vapor generation over the evaporator zones is easily perceptible (figure 13), resulting in a local pressure surplus compared to the adiabatic zones.

The FHP capillary limit was not reached because the effective pressure drops were about $\Delta P=\Delta P_{l}+\Delta P_{v}=2436 \mathrm{~Pa}$, while the maximum capillary pressure developed by the wick structure was around $\Delta P=2513 \mathrm{~Pa}$. This pressure drop was determined according to the Young-Laplace simplified law.

\section{Conclusion}

The model used in this study aimed to determine the transient thermal performances of a heat pipe used to cool the electronic components in a starter-alternator. According to its degree of refinement and complexity, the model proposed here could be used for different electronic component cooling applications. This complex and precise model is 
able to predict the reliability and quality of electronic cooling. It permits precise predictions and an optimized heat pipe design and thus helps to avoid local hot points.

This study continues in order to improve the transient 3DTH model by coupling it with a micro-region model, which will better take into account the liquid-vapor interface phenomena. Indeed, the micro-film region is a preferred heat transfer zone in which the capillary and adhesion molecular forces are the same order of magnitude. The heat exchanges within these zones are very important because of the very slight thickness of the liquids. Integrating this micro-model into the macro-model will allow us to determine precisely the thickness of the liquid meniscus and the effective evaporationcondensation conductance [17].

\section{Acknowledgements}

The authors would like to acknowledge the financial support provided by FuturElec, the National Center for Techonological Research; the Nord/Pas-de-Calais Region; the FEDER program; and Valéo Electical Systems.

\section{References}

[1] www.valeo.com

[2] Xuan Y., Hong Y., Li Q., Investigation on transient behaviours of flat plate heat pipes, Exp. Thermal and Fluid Science, 28 (2004), 249-255.

[3] Basiulis A., Minning C.P., Improved reliability of electronic circuits through the use of heat pipes, Proceedings of 37th National Aerospace and Electronic Conference Dayton, OH, 1985.

[4] Garimella S.V., Sobhan C.B., Recent advances in the Modeling and Applications of Nonconventional Heat pipes, Advances in Heat Transfer, 35 (2001), 249-308.

[5] Xiao B., Faghri A., A tree-dimensional thermal-fluid analysis of flat heat pipes, Heat Mass Transfer, 51(2008) 3114-3126.

[6] Faghri A., Heat Pipe Science and Technology, Taylor \& Francis, 1994.

[7] Reay D., Kew P., Heat-Pipes-Theory-Design-and-Applications, ButterworthHeinemann, Oxford, UK, 2006. 
[8] Sonan R., Modélisation du comportement thermique transitoire d'un caloduc: application au refroidissement de l'électronique associée à un alterno-démarreur, Ph.D. thesis, Université de Valenciennes, France, 2009.

[9] Sobhan C. B., Garimella S. V. and Unnikrishnan V. V., A Computational Model for the Transient Analysis of Flat Heat Pipes, Proceedings of Inter Society Conference on Thermal and Thermomechanical Phenomena in Electronic Systems, ITHERM, Las Vegas, Nevada, , (2000), 106-113.

[10] Lefèvre F., Lallemand M., Coupled thermal and hydrodynamic models of flat micro heat pipes for the cooling of multiple electronic components, Int. J. Heat Mass Transfer, 49 (2006) 1375-1383.

[11] Huang L., El-Genk M.S., Tournier J.M., An experimental performance of an inclined water heat pipe with a screen wick, Proceedings of ASME National Heat Transfer Conference, Atlanta GA, Heat Pipes and Capillary Pumped Loops, HTD-vol 236, (1993), 87-92

[12] Bejan A., Convection Heat Transfer, Wiley, New York, 1984.

[13] Fletcher C. A. J., Computational Techniques for Fluid Dynamics, second ed., Springer-Verlag, Sydney (1991) 330-374.

[14] Sonan R., Harmand S., Pellé J., Léger D., Fakès M., "Transient thermal and hydrodynamic model of flat heat pipe for the cooling of automotive electronic components", International Journal of Heat and Mass Transfer, 51 (2008) 6006-6017.

[15] Jaballah S., Sammouda H., Belghith A. Numerical simulation of mixed convection in a channel irregularly heated and partially filled with a porous medium, Journal of Porous Media, 3, (2008), 247-257.

[16] Chen Y.S., Chien K. H. ,Hung T.C. .,Wang C. C., Ferng Y. M. and Pei B. S. "Numerical simulation of a heat sink embedded with a vapour chamber and calculation of effective thermal conductivity of a vapour chamber", Applied thermal engineering, 29 (2009) 2655-2664.

[17] Sefiane K., Bennacer R., El-Ganaoui M.,and Buffone, C. al. Numerical investigation of the role of non-uniform evaporation rate in initiating Marangoni convection in capillary tubes, International Journal of Numerical Methods for Heat and Fluid Flow, 7, (2004) 877-890. 
Highlights

$>$ In this study we model a Flat Heat Pipe (FHP) designed for the cooling of electronic components $>$ This model is a transient model, coupling 3D thermal and hydrodynamic models $>$ The model makes it possible to obtain the FHP wall transient temperatures $>$ Transient pressures, velocities and temperatures in liquid and vapor phases are also obtained $>$ We conclude that FHP is more efficient for long than very short thermal cycles. 


$$
-\lambda_{\mathrm{w}}\left(\frac{\partial \mathrm{T}}{\partial \mathrm{z}}\right)_{\mathrm{z}=\mathrm{L}_{\mathrm{z}}}=\phi_{\text {in }}
$$

Electronic components

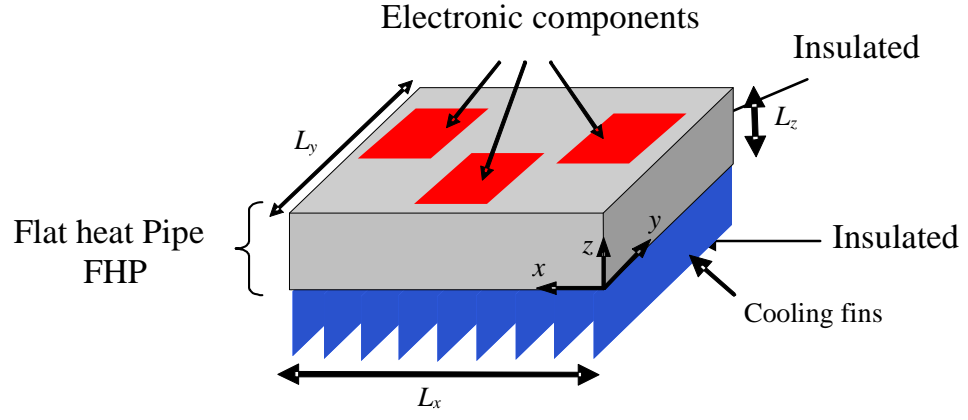

$$
-\lambda_{\mathrm{w}}\left(\frac{\partial \mathrm{T}}{\partial \mathrm{z}}\right)_{\text {upper wall }}=\mathrm{h}_{\mathrm{eq}, \mathrm{w}}\left(\mathrm{T}-\mathrm{T}_{\mathrm{sat}}\right)+\partial^{2} \dot{\mathrm{m}}_{\mathrm{e}} \mathrm{C}_{\mathrm{pl}} \mathrm{T}_{\text {sat }}=\phi_{\text {upper wall }}
$$

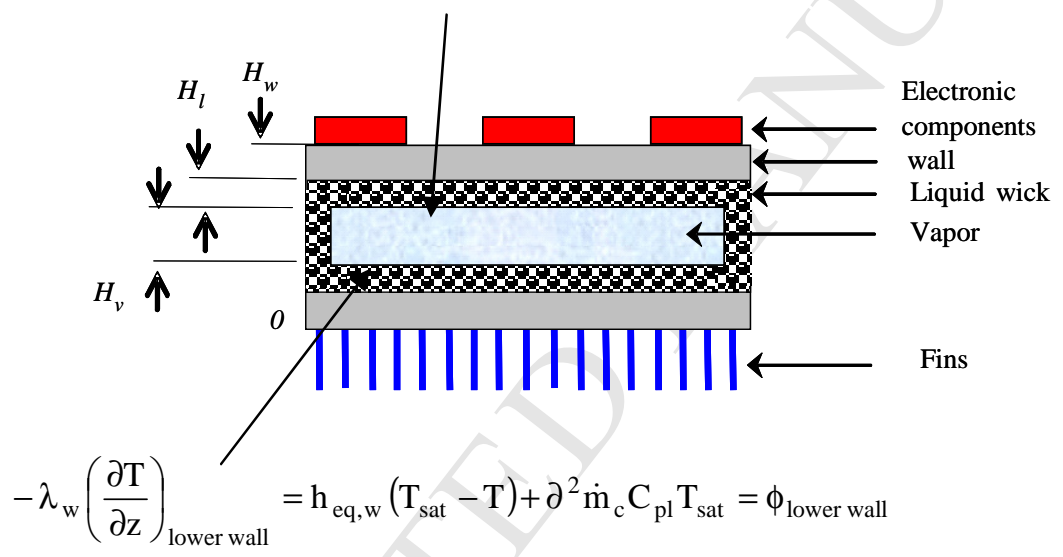

Figure 1. Flat Heat pipe 


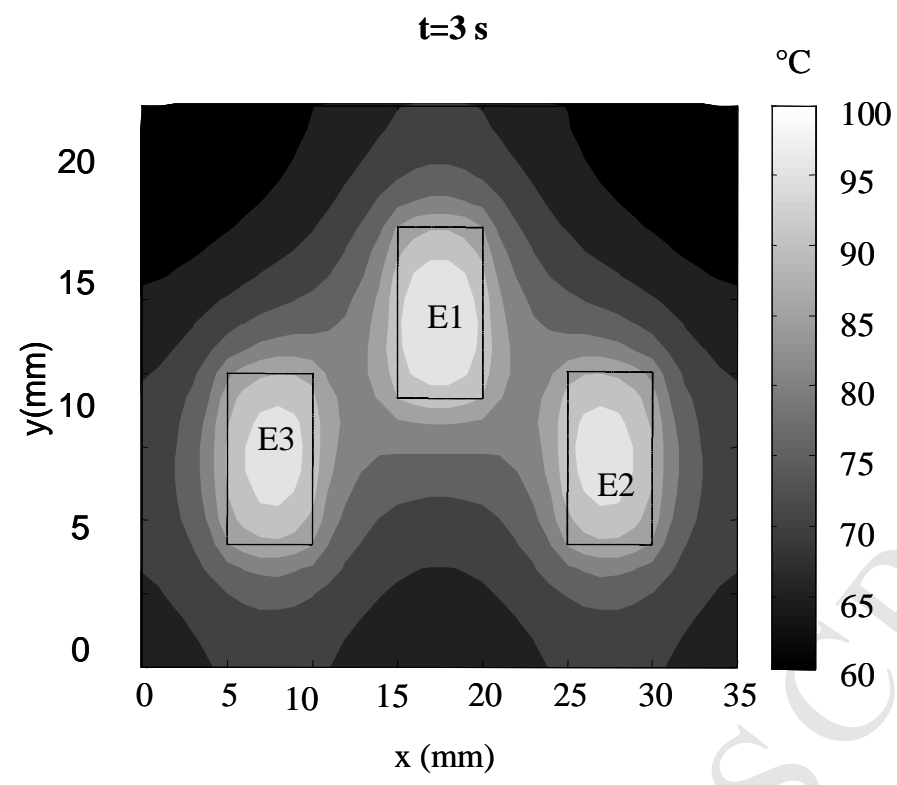

Figure 10. Temperature distribution on the wall of the FHP 

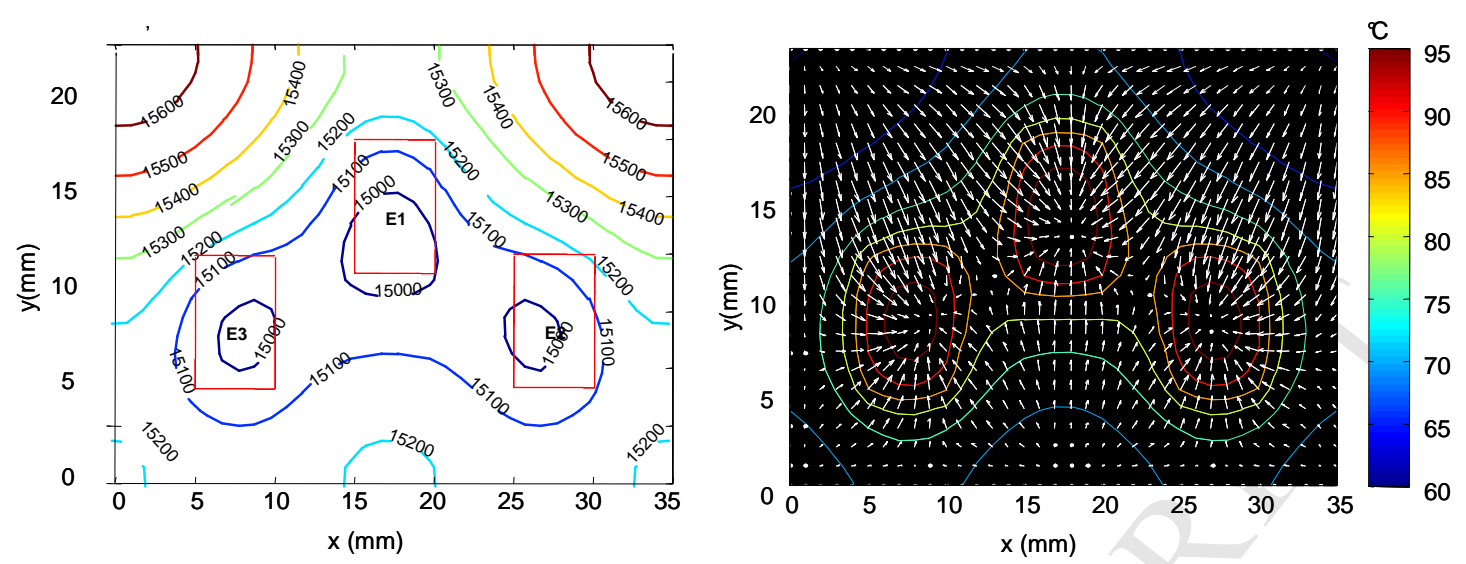

Figure 11. Liquid Pressure, velocity and temperature on the upper wall at $\mathrm{t}=3 \mathrm{~s}, \Delta \mathrm{p}=715 \mathrm{~Pa}$ and $\mathrm{v}_{\max }=0.004 \mathrm{~m} . \mathrm{s}^{-1}$ 


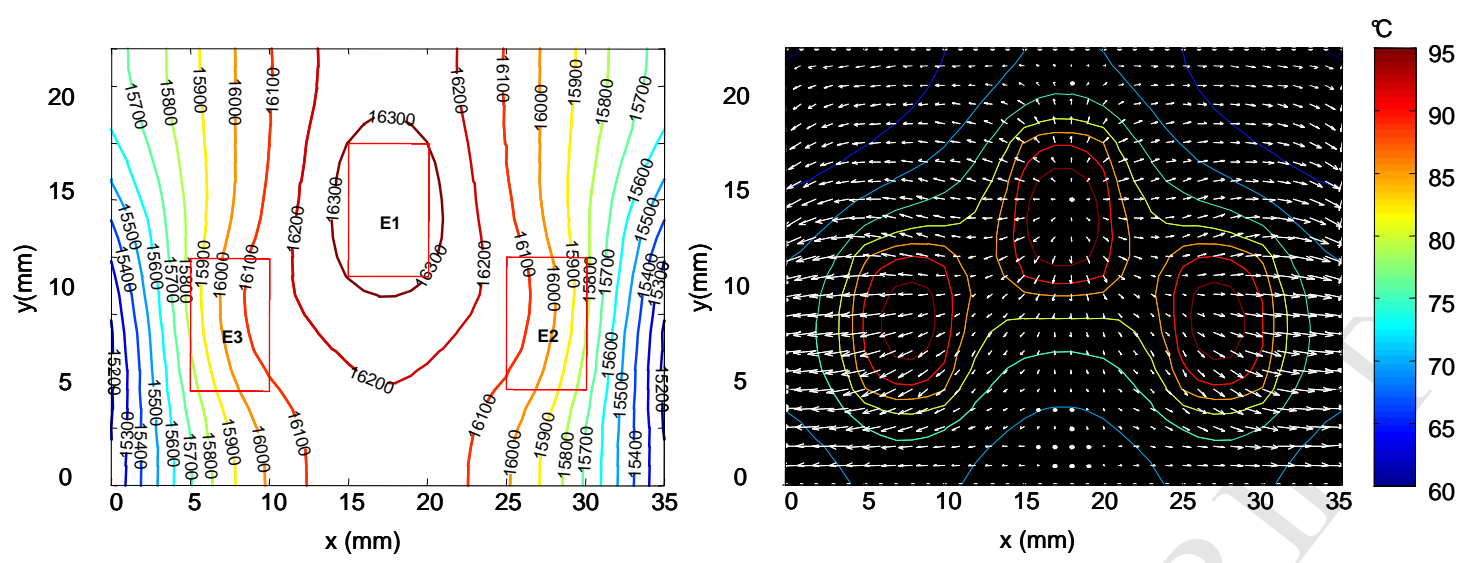

Figure 12. Liquid Pressure, velocity and temperature on the lower wall at $\mathrm{t}=3 \mathrm{~s}, \Delta \mathrm{p}=1212 \mathrm{~Pa}$ and $\mathrm{v}_{\max }=0.007 \mathrm{~m} . \mathrm{s}^{-1}$ 

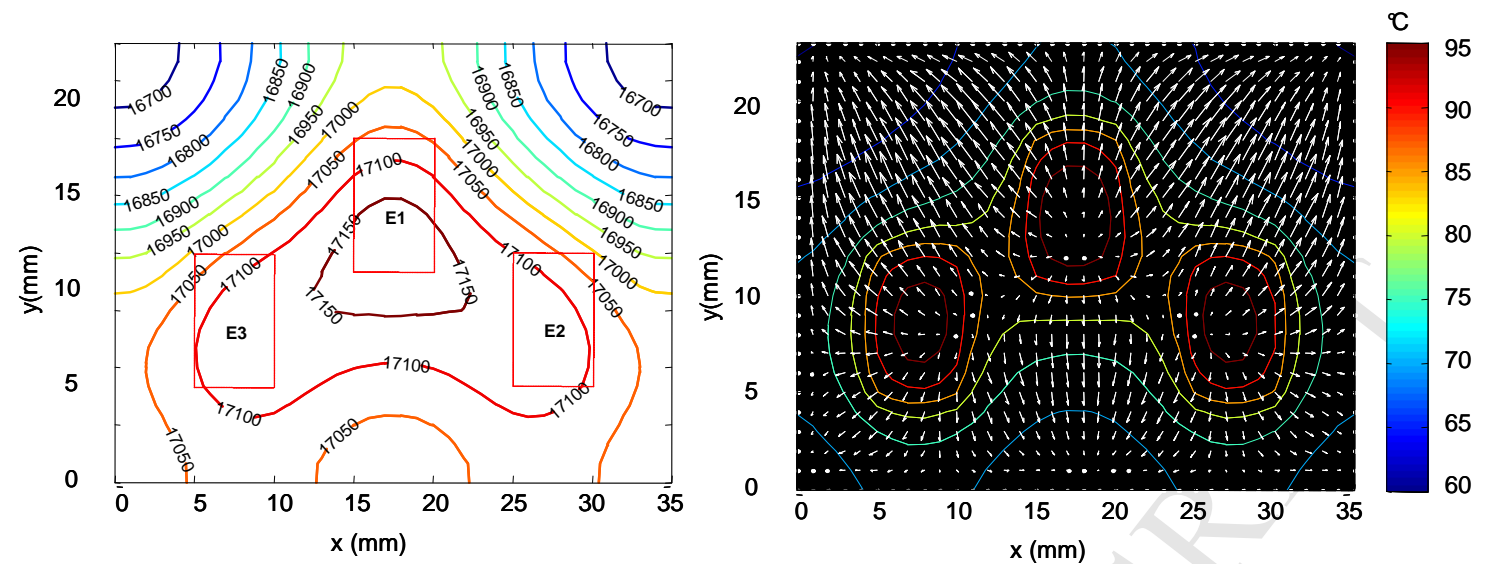

Figure 13. Vapor pressure, velocity and temperature distribution, $v_{\max }=61 \mathrm{~m} \cdot \mathrm{s}^{-1}$ 


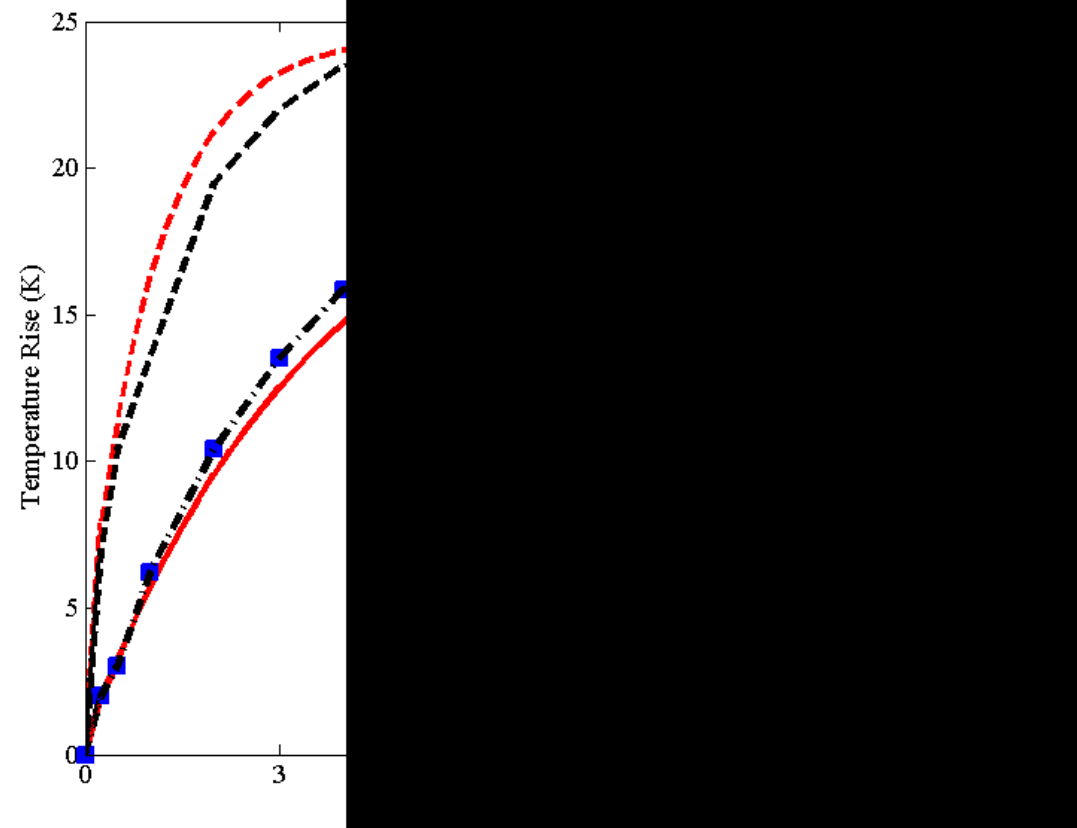

Figure 2a. Comparison between the numerical results, experimental work and results of Chen et al. [16] for the evolution of the maximum heat pipe temperature rise with time.

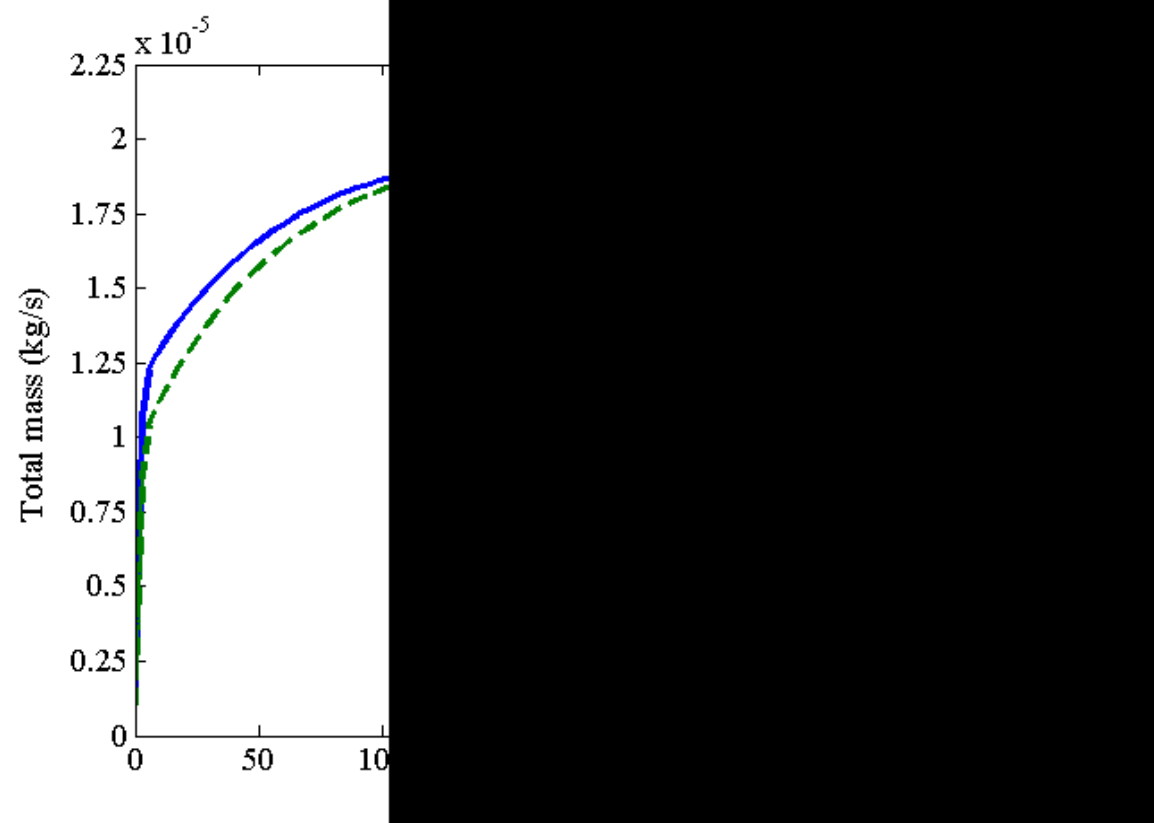

Figure 2b. Evolution of the total mass evaporated and condensed with time in case of neglecting the thickness of heater and insulation. 


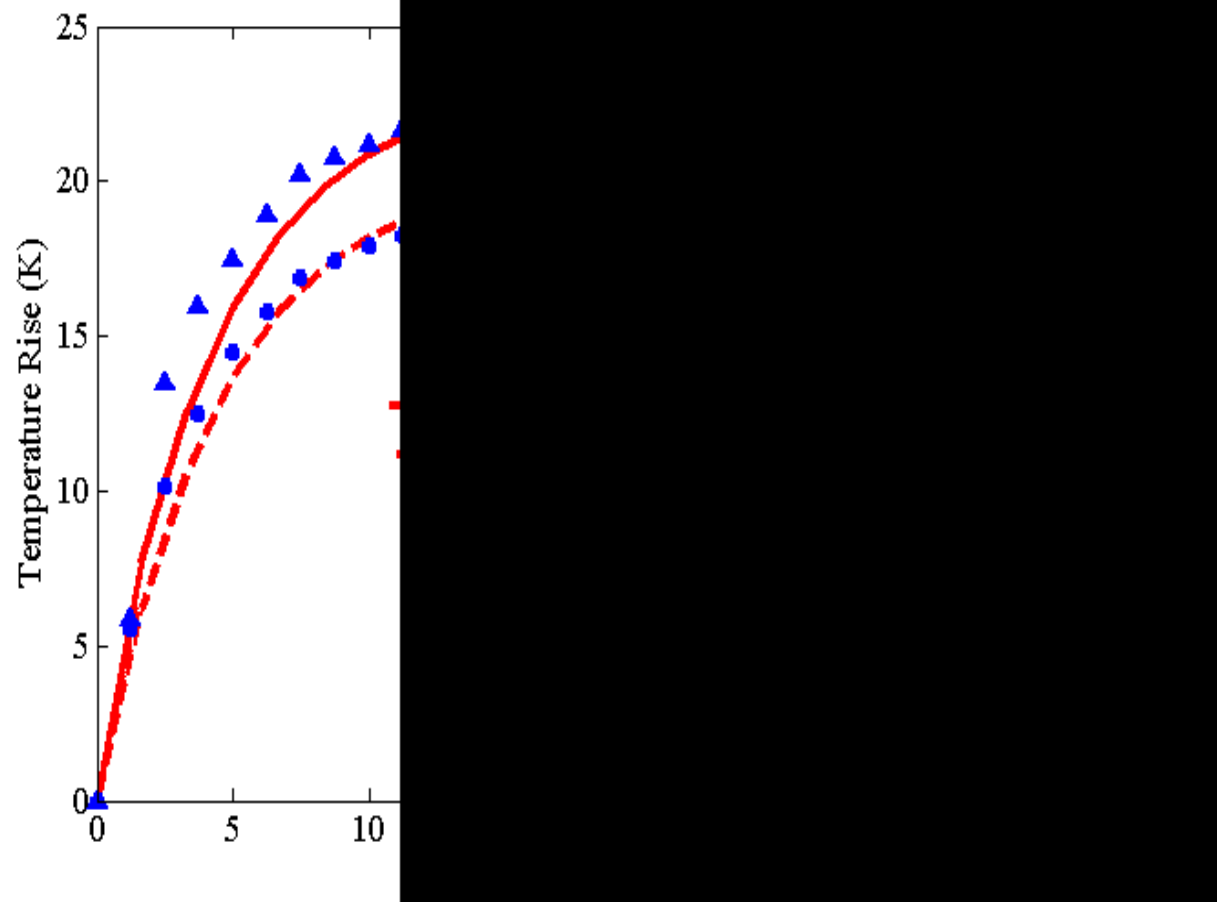

Figure 3a. Comparison of the numerical results and experimental work of Chen et al [16] for the evolution of the evaporator and condenser surface temperature at power input $50 \mathrm{~W}$ and heater surface area $20 \times 20 \mathrm{~mm}^{2}$.

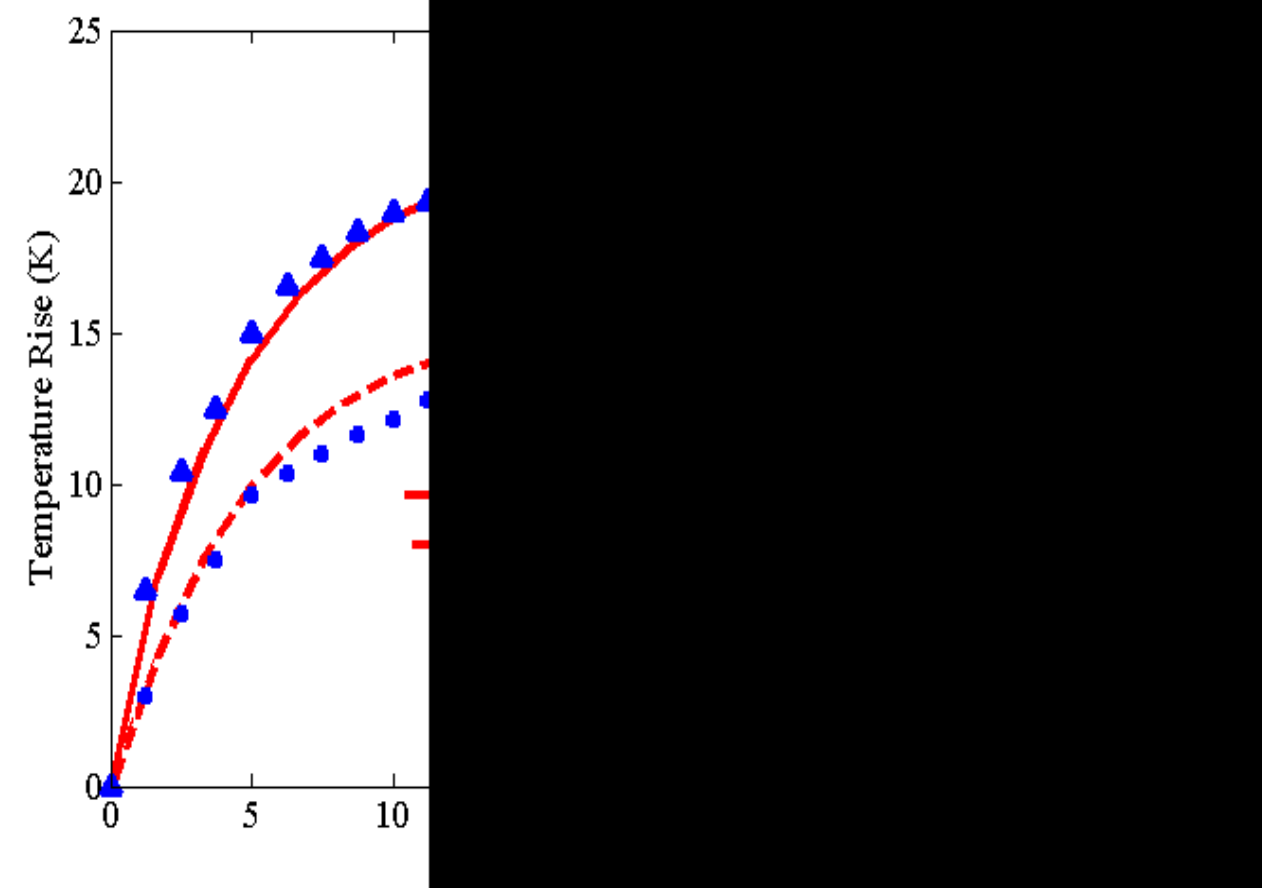

Figure 3a. Comparison of the numerical results and experimental work of Chen et al [16] for the evolution of the evaporator and condenser surface temperature at power input $40 \mathrm{~W}$ and heater surface area $10 \times 10 \mathrm{~mm}^{2}$. 


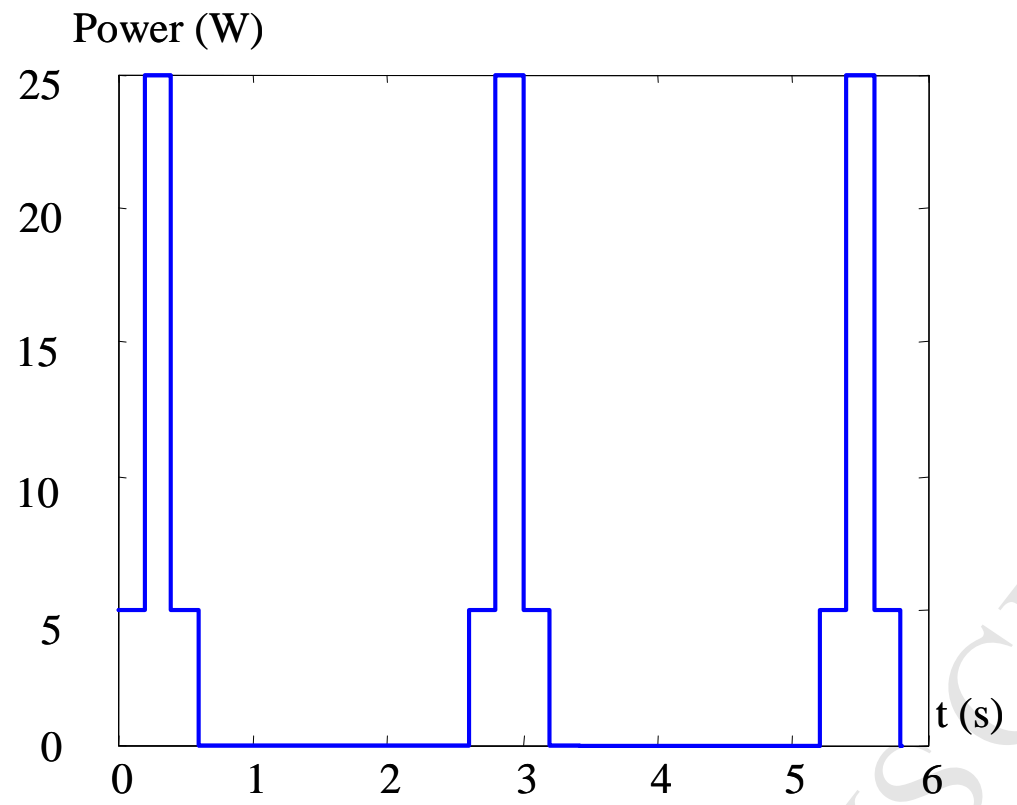

Figure 4. Power generated by the electronic components 
Temperature ${ }^{\circ} \mathrm{C}$

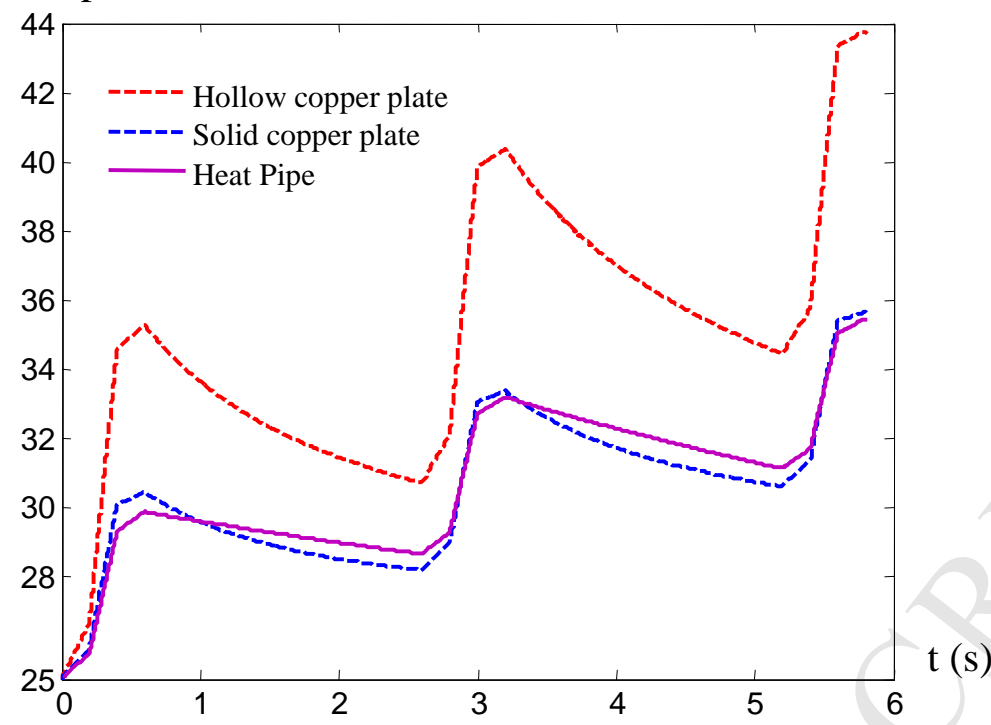

Figure 5. Evolution of the evaporator temperature 


\section{Temperature ${ }^{\circ} \mathrm{C}$}

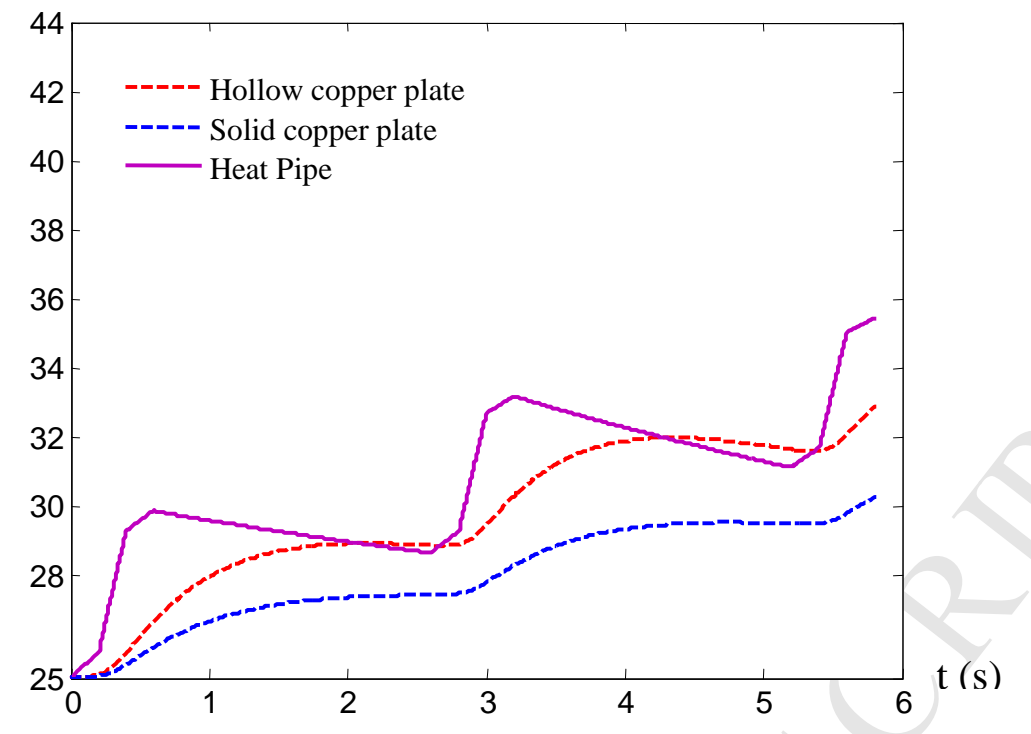

Figure 6. Evolution of the condenser temperature 
K

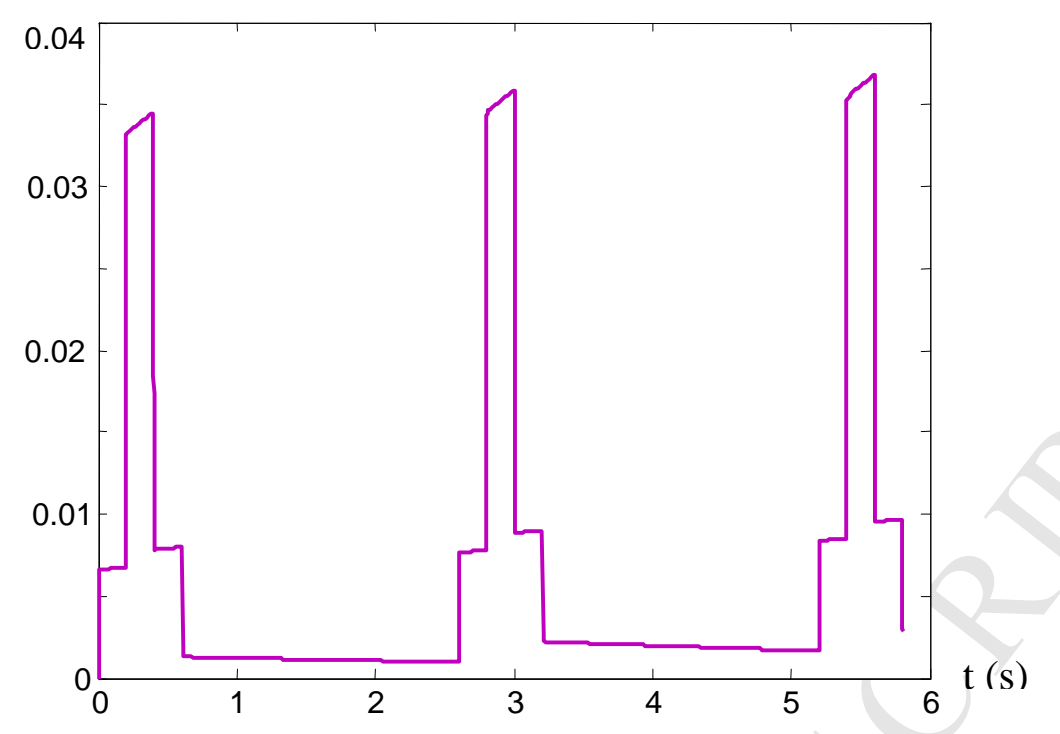

Figure 7. Evolution of $\mathrm{T}_{\mathrm{e}}-\mathrm{T}_{\mathrm{c}}$ 


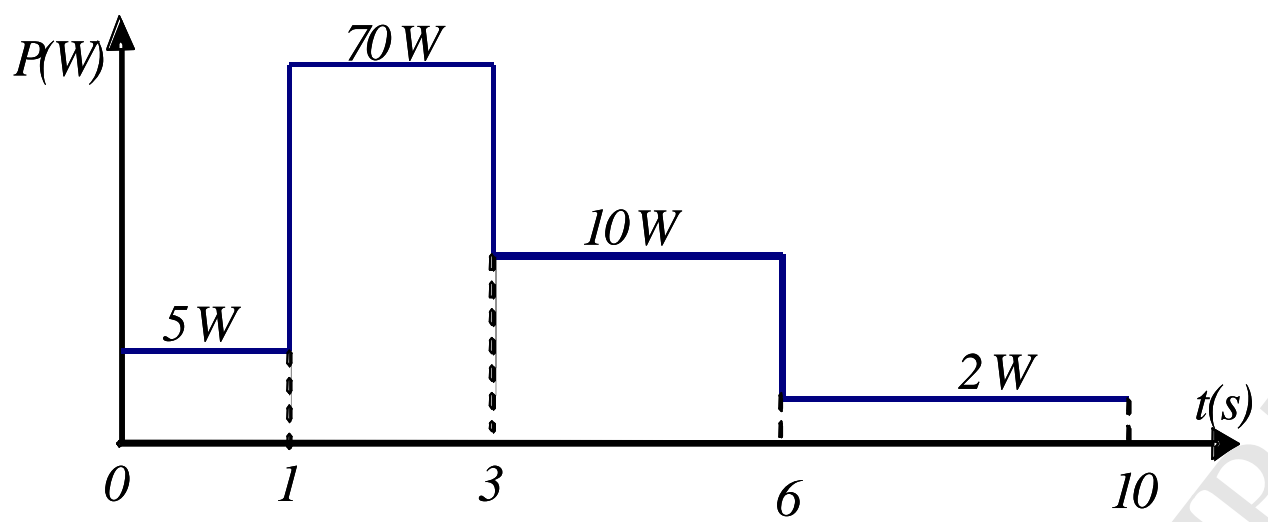

Figure 8. Thermal heat power dissipated 


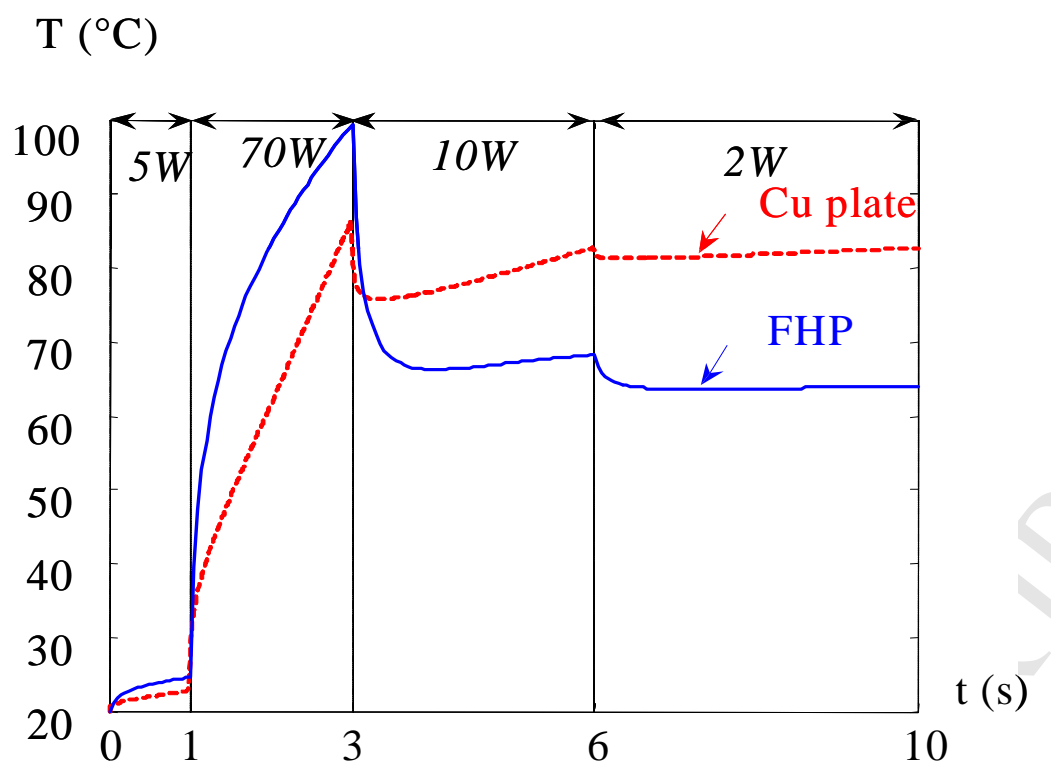

Figure 9. Comparison of the temperature of the FHP upper and of a solid copper plate 